\title{
The role of stereotypes and meta-stereotypes attribution in expressing threat related to social identity: the perspective of the need based model
}

\begin{abstract}
According to the needs-based model of socio emotional reconciliation, after a conflict, victims of hostilities suffer from a threat to their social identity as meaningful and powerful actors and members of the perpetrator group experience threat to their identity as moral actors. ${ }^{1}$ These threats felt by victims and perpetrators can be expressed in the daily interactions through the stereotypes and meta-stereotypes attributions which play a big role in ingroup definition and evaluation ${ }^{2,3}$ and are structured along three dimensions: the dimension of sociability, dimension of competence and dimension of morality, ${ }^{4-6}$ When these identity threats are not addressed they can impede reconciliation process. In the present interview study we will explore the way the identity threats whose suffer victims and perpetrators of genocide against Tutsis according to NBM, are expressed in stereotypes and meta-stereotypes attribution and investigate if the meta-stereotype attributions have confirmed the stereotype attributions. It also examined if the stereotypes and metastereotypes that survivors and non-victims attribute to each other are structured along three dimensions: moral, social and agency, play a role in defining identity and determining its value.

The findings have shown that the stereotypes and meta-stereotypes that survivors and non-victims attribute to each other are structured along three dimensions: moral, social and agency play a role in defining identity and determining its value. The meta-stereotype attribution have confirmed the stereotype attributions and expressed identity threats whose suffer victims and perpetrators of genocide against Tutsis according to NBM. During the period following genocide the members of the survivors group were often stereotypically perceived and expected to be perceived by non-victims as cold, immoral and with valorized status. On the contrary, non-victim groups with inferior status were perceived and expected to be perceived as immoral and cold in the past. However at the period we conducted interview the stereotypes and meta-stereotypes attributed to non- victims has changed in a positive way.
\end{abstract}

Volume 2 Issue $3-2018$

Clémentine Kanazayire (Phd)

Department of Mental Health, University of Rwanda, Rwanda

Correspondence: Dr Clémentine Kanazayire, Department of Mental Health Department , University of Rwanda, KigaliRwanda,Tel + 250-78-848.89.10,Email kanacle@yahoo.fr

Received: April II, 2018 | Published: June 27, 2018

\section{Introduction}

The genocide perpetrated against the Tutsi resulted in the deaths of about one million Tutsi and Hutu victims who were opposed to the genocidal ideology, killed by extremist Hutus and Interahamwe militia. As in other post-war and post-genocide cases, the Rwandan government, set up on July 19, 1994, faced the major challenge of re-establishing relations between groups previously involved in the conflict. $^{7}$

Various strategies exist to transform relations between these groups and promote post-conflict reconciliation. ${ }^{8,9}$ In order to restore harmonious relations, certain psychological models focus in general on one or two psychological elements involved in reconciliation, such us identity change, or restoration of relations based on mutual trust. Others emphasize on mutual acceptance, forgiveness and taking away emotional barriers. ${ }^{10}$ According needs-based model of socio emotional reconciliation, ${ }^{11}$ after a conflict, victims and perpetrator of hostilities suffer from different threats to their social identity. ${ }^{1}$ Theses identity threats have to be addressed and overcame in order to favor the reconciliation between the groups who were in conflict.

The needs-based socio-emotional reconciliation model (NBM) is best used in a context where the distinction between perpetrators and victims is clear. ${ }^{11}$ According to the needs-based reconciliation model, at the end of a conflict, victims suffer a threat to their identity as a powerful actor, ${ }^{11,12}$ and are likely to have feelings of victimization or anger. ${ }^{13}$ On the other hand, the perpetrators suffer from their negative moral image ${ }^{11-15}$ and fear of being rejected by the moral community of belonging. ${ }^{1,18}$

These identity threats can cause different motivations for perpetrators and victims. ${ }^{11}$ The humiliated victims may revenge themselves to restore the power of their groupor persecute perpetrators to recognize the wrongs and injustices they have caused to members of the victim group. ${ }^{11}$ In order to downplay their culpability, the members of the perpetrator group may, for their part, deny the painful consequences of their actions and / or their responsibilities for causing harm to the victims. ${ }^{19-22}$ This unilateral strategy allows one group to respond to its own needs and face threats to their identity, but they impede reconciliation. Nevertheless, an exchange interaction that may open to reconciliation is the one through which victims and perpetrators satisfy each other's needs for empowerment and acceptance. In that line, the actors can recognize their responsibilities, apologize, offer compensations or reparations, adopt positive attitudes towards members of the victim group, demonstrate empathy ${ }^{11}$ and build friendships. ${ }^{1}$ All these actions and attitudes of members of the perpetrator group will allow victims to restore the power and selfcontrol they had lost during the period of victimization. ${ }^{1,23}$ Victims can also forgive, accept compensation and collaborate with perpetrators. By giving pardon to the perpetrators, the victims satisfy the need for 
perpetrators to restore their positive moral image which contributes to their integration into the social community. ${ }^{11}$ In this article, we didn't focus on apology-forgiveness cycle, the present article explored if in the aftermath of genocide against Tutsis, the victims and members of perpetrators group suffered from the identity threats and the way they expressed its through the stereotypes and meta-stereotypes attribution.

Extending the needs-based model to the dimensions along which are structured stereotypes and metastereotype attributions

The needs-based model suggests that victims of hostilities experience threat to their agency. At the same time, members of perpetrator group suffer from threats to their identity as moral actors. They feel morally inferior and are concerned by social exclusion of their community moral. ${ }^{1}$ According to Shnabel ${ }^{24}$ the need based model is built on social-psychological theorizing that postulates two fundamental dimensions along which social judgment ${ }^{24}$ and stereotypes ${ }^{5,25}$ are structured: the agency dimension, and the moralsocial dimension. ${ }^{5,6,24,26-30}$

The two dimensions structure stereotypes at the individual level ${ }^{28-32}$ and social group level ${ }^{33,34} \mathrm{~A}$ conceptualization of these dimensions shows that the agency dimension represents traits such as strength, competence and influence. The moral-social dimension refers to traits such as morality, warmth, and trustworthiness. ${ }^{5,26,36}$ The currents study has shown the particularity and the importance of the morality dimension, which was for a longtime neglected in the traditional view within social psychological theorizing., ${ }^{47}$ proposed to consider morality as another dimension and not as a part of the sociability dimensions. For these authors, the morality dimension (honest, trustful) is different from the sociability dimension (warm) and agency (competent, intelligent, and influent). In the most of these studies, the success of the group in domains like the morality and sociability dimensions was not considered as important in in-group evaluation. ${ }^{6}$ Only the agency dimension was considered to be an important basis in positive in-group evaluation ${ }^{38,39}$ and for personal self esteem. ${ }^{40} \mathrm{~A}$ valorized status in the competence domain was associated with a very strong in-group identification and in-group favoritism compared to the out-group ${ }^{41-43}$ However, current research has demonstrated that morality was also strongly associated to ingroup identification, in-group pride and positive evaluation. ${ }^{4,44}$ These three dimensions, competence, morality and sociability, play an important role in intergroup relations and intervene in how people evaluate in-group and out-group. Intergroup conflicts are not only manifested in direct violence in situations such as genocide and war but also in unequal social relations that favor some groups while depriving others. ${ }^{45}$ These inequalities are expressed in attribution of stereotypes to the out-group. Advantaged groups with a superior status are often stereotypically perceived as competent but cold and immoral. On the contrary, disadvantaged groups with inferior status are perceived as warm but incompetent. ${ }^{46}$

The needs-based model's logic postulates that in the context in which group inequality is perceived as illegitimate, the needs and identity threats faced by advantaged-group and disadvantaged-group members should be the same to those of perpetrators and victims. ${ }^{23}$ An experimental study conducted by ${ }^{47}$ on students from clinical psychology department confirmed this logic. The findings from this study have shown that in the condition of illegitimate status difference, the need for agency of the disadvantaged group members was higher than among the advantaged group, while the contrary pattern was observed for the need for acceptance. However, no study has been conducted in order to investigate if the same logic of the needs based model is functioning also in stereotype and meta-stereotype attribution to the out-group between victims and members of the perpetrator group. Our concern in this study was to explore in a post genocide against Tutsis situation, the way the identity threats whose suffer victims and perpetrators according to Needs Based Model are expressed in the three dimensions along which are structured the stereotypes and meta-stereotypes attribution and its evolution over the time.

\section{Objectives of the study}

a) To explore the way the identity threats whose suffer victims and perpetrators after genocide against Tutsis according to NBM are expressed in stereotypes and meta-stereotypes attribution along three dimensions: moral, social and agency and its evolution along the time.

b) To examine whether these stereotypes and meta-stereotypes that survivors and non-victims attribute to each other have changed over the time.

c) To investigate if the meta-stereotype attribution have confirmed the stereotype attributions and

\section{Method}

\section{Participants}

The study was conducted in 2011 at the Kibungo Institute of Agriculture, Technology and Education (INATEK) in the eastern province of Rwanda. The participants were students of the Faculty of Psychological Sciences and Education, 3rd and 4th year of license, and of Rwandan origin. The sample comprises 20 participants from the 300 participants who had previously participated in a quantitative study: 10 survivors and 10 non-victims. We conducted interviews with about 20 participants. The interview lasted between 20 and 30 minutes. Participants' ages ranged from 22 years to 51 years at the time of the survey. The mean age 31 years with the standard deviation of 8.08 .

\section{Procedure}

Following the collection of data for the quantitative study (Chapter 3 ), we returned to the Institute of Agriculture, Technology and Education of Kibungo (INATEK) to inform the Dean of the Faculty of Psychology and educational sciences that we needed participants for a qualitative study. The Dean agreed to give us access to the students and asked the teachers to facilitate the recruitment. Explanations on the study were provided to the students during the break to clarify that the persons eligible for participation were those who lived in Rwanda during the genocide and who participated in the first study. Many of the participants who were willing to participate remained at the end of the course and signed up on a sheet of paper. Only 20 participants were selected, the first 10 survivors and the first 10 non-victims on the list. Participants signed a free and informed consent form. Five of them took the interview on the same day and the others made an appointment. For obvious reasons linked with the post genocide context, it was not possible to use ethnic group identity. We use term "genocide survivors" and "non survivor" : "a genocide survivor is anyone who was chased from 1/10/1990 until 31/12/1994 because 
of his/her ethnicity or ideology to fight against the genocide of the Tutsi". Non victims (people who were in Rwanda during genocide against Tutsi but were not persecuted)

\section{Interview guide}

Semi-structured interviews were conducted in 2011 and conducted in Kinyarwanda. Some were conducted at INATEK and others at the Kigali Health Institute. All participants responded positively to the interview request. The interview lasted between 20 and 30 minutes. The interview guide was developed on the basis of documentation relevant to the subject and purpose of the study. As part of a longer interview, participants were asked to specific questions about perceptions:

a) Try to describe how you perceived the members of survivor group/ non-victim group (people who were in Rwanda during genocide against Tutsi but not persecuted) during the period just after genocide against Tutsis (from 0 to 3 years).

b) Try to describe how you thought members of the survivor group/ non-victim (people who were in Rwanda during genocide against Tutsi but not persecuted) perceived the members of your group during the period just after genocide against Tutsis (from 0 to 3 years).

c) Try to describe 17 years after genocide against Tutsis how you perceive the members of survivor group/ non-victim group (people who were in Rwanda during genocide against Tutsi but not persecuted).

d) Try to describe 17 years after genocide against Tutsis how you think members of the survivor group/ non-victim (people who were in Rwanda during genocide against Tutsi but not persecuted) perceive the members of your group.

\section{Analysis method}

Since our aim was to explore in a post genocide against Tutsis situation, the way the identity threats whose suffer victims and perpetrators according to Needs Based Model are expressed in the three dimensions along which are structured the stereotypes and metastereotypes attribution and its evolutions over time, we carried out a thematic analysis (Braun and Clark, 2006). This analysis implies an identification of the responses taking into account the questions being asked. After a discussion with colleagues on the categories identified in the interviews, the main themes and the sub-themes were differentiated. The schemas below, provides a detailed analysis of the categories, themes and sub-themes that guided us in the presentation of the results. Figure 1, below, provides a detailed analysis of the categories, themes and sub-themes that guided us in the presentation of the results.

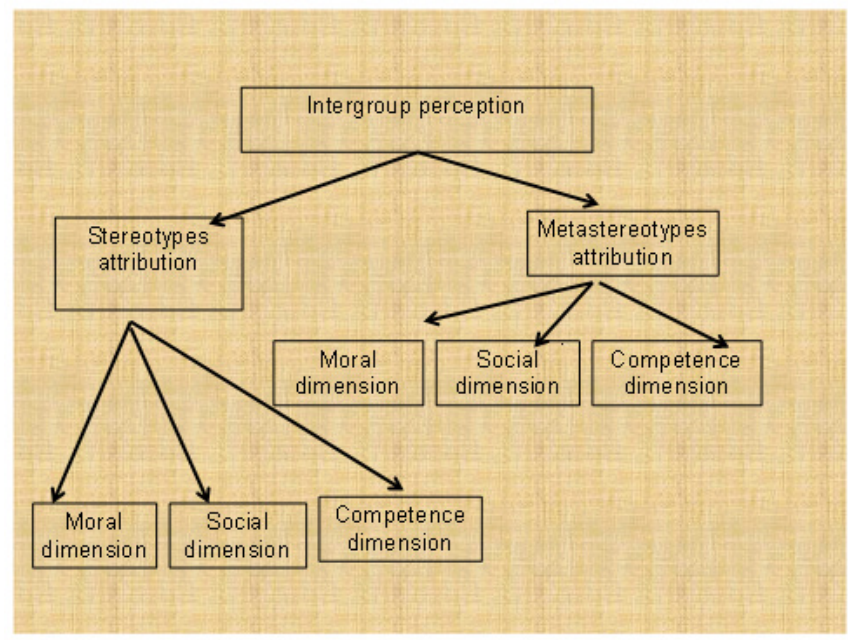

Figure I Provides a detailed analysis of the categories, themes and sub-themes that guided us in the presentation of the results.

\section{Results}

The objectives of this study was to explore in a post genocide against Tutsis situation, the way the identity threats whose suffer victims and perpetrators according to Needs Based Model are expressed in the three dimensions along which are structured the stereotypes and metastereotypes attribution and its evolution along time. We presented the different stereotypes and meta-stereotypes attributed to non-victims and survivors and structured its along the dimension of competence, sociability and morality.

\section{Stereotypes attributed to non-victims by survivors}

The stereotypes that the survivors attributed to the non-victims can be grouped in two dimensions: morality and sociability. These stereotypes have a negative connotation and highlight the immorality and coldness of non-victims. Nine survivors out of ten who attributed these stereotypes mention a certain evolution as the years progressed and reported that at the moment of the interview things were going well. Non-victims and survivors live well together, non-victims are considered as normal people, like other people. Two of these nine survivors reported that the non-victim group is heterogeneous. They pointed out various subgroups according to which stereotypes were attributed.

\section{Moral dimension}

The stereotypes that the survivors attributed to the non-victims concerned the moral and sociability dimensions. Immediately after the genocide, the survivors perceived the non-victims as genocide 
perpetrators. This attribution is reflected in participant 2: "I can give a close example. Immediately after the genocide, when a survivor saw a non-victim, he perceived it as a "haduyi". Currently survivors and non-victims get along well. A survivor knows that he is a victim of the atrocities and a non-victim knows that they have done wrong things but that does not prevent them from living well together ". Participant 1 does not talk about this change but stresses that it should not be generalized to all non-victims: "Because mine were massacred during the genocide, I perceived all Hutus as "Interahamwes". But as the days progress, I realize that there are members of the Hutu group who are innocent who did not participate in the genocide and who regret being Hutu. "

\section{Social dimension}

In terms of sociability, the non-victims were considered by the survivors to be cold. But they acknowledged that relationships have evolved into the warmth over time: "In the past, just after the genocide, I did not want to talk to the non-victims. I had repulsion and horror for them. As the years passed, there was something that changed and I began to consider them as other people. I tell myself that even if it happened, all the non-victims did not do that "(Int 12). Another participant mentioned that hatred and suspicion prevailed immediately after the genocide. These feelings have disappeared over the years: "... in the past, we perceived them as disgustful people, who did not feel us. There were always suspicions between us. (..). As we walked along and conversed with them, we realized that we were the same. In the past, non-victims were afraid to approach us. Now we could we be comfortable with them "(Int 16).

Table I Demographic characteristic of participants

\begin{tabular}{|c|c|c|c|}
\hline Participants & Status & Sex & $\begin{array}{l}\text { Age at interview } \\
\text { moment in } 2011\end{array}$ \\
\hline $\mathrm{N}^{\circ} \mathrm{I}$ & Survivor & Female & 22 years \\
\hline$N^{\circ} 2$ & Survivor & Male & 23 years \\
\hline$N^{\circ} 3$ & Survivor & Male & 25 years \\
\hline$N^{\circ} 4$ & Survivor & Male & 24 years \\
\hline$N^{\circ} 5$ & Survivor & Female & 51 years \\
\hline$N^{\circ} 6$ & Survivor & Female & 48 years \\
\hline$N^{\circ} 7$ & Survivor & Male & 31 years \\
\hline$N^{\circ} 8$ & Survivor & Female & 31 years \\
\hline$N^{\circ} 9$ & Non-victim & Female & 30 years \\
\hline$N^{\circ} 10$ & Non-victim & Male & 25 years \\
\hline $\mathrm{N}^{\circ} \mathrm{II}$ & Non-victim & Female & 36 years \\
\hline$N^{\circ} 12$ & Survivor & Male & 28 years \\
\hline$N^{\circ} 13$ & Non-victim & Female & 26 years \\
\hline$N^{\circ} 14$ & Non-victim & Female & 36 years \\
\hline$N^{\circ} 15$ & Non-victim & Female & 36 years \\
\hline$N^{\circ} 16$ & Survivor & Male & 24 years \\
\hline$N^{\circ} 17$ & Non-victim & Female & 26 years \\
\hline$N^{\circ} 18$ & Non-victim & Female & 27 years \\
\hline$N^{\circ} 19$ & Non-victim & Male & 28 years \\
\hline$N^{\circ} 20$ & Non-victim & Male & 43 years \\
\hline
\end{tabular}

No all survivors perceived all members of the non-victim group in the same way; some survivors attributed the stereotypes to the different subcategories of the non-victim group: "As the days progressed we were able to realize that non-victims are different. There are those who committed the atrocities and others who did not. The proof is that there are people who have been rewarded for hiding the survivors. These people who were able to hide the survivors are in good relations with the survivors. Those who have done nothing to help and save the survivors live with the survivors because they have no other choice. They always have a nasty heart. They are of them who are wolves and try to present themselves as lambs. There are others who have not been able to help the survivors but are not bad. These are Rwandans like so many others and live easily with the survivors "(Int 6). All the stereotypes that the survivors attribute to the non-victims are negative and relate to the period that directly followed the Tutsi genocide. Although most survivors report that after the genocide against Tutsis survivors perceived non-victims as cold and immoral, this was in the past and things have changed. This survivor mentions that non-victims should not be generalized. He goes so far as to announce three different categories of non-victims, including the category of the Heroic Helpers, who have been recognized and rewarded for saving people. These are called "indekemwa" (moral exemplars) or "abarinzi b'igihango" (friendship protector). According to this participant, the relationships between survivors and nonvictims depend on the category of non-victims to which they belong. In the next section we will examine the way non-victims think they are perceived by survivors.

\section{Meta-stereotypes attributed to survivors by non- victims}

In contrast to our predictions, no meta-stereotypes of competence were mentioned by non-victims. Briefly, six out of ten non-victims thought that they were perceived by the survivors as cold and immoral during the post-genocide period. They reported that at the time of the investigation things were going well. In the course of this investigation, the non-victims thought that they were considered as people who could help the survivors. Two out of ten non-victims point out that they cannot pronounce themselves on meta-stereotypes held by others with the pretext that they can't know what others think. However, only one non-victim participant did not mention any change. Finally, three out of 10 non-victims stressed the variability of their in-group. They did not think that survivors perceived all members of the nonvictim group in the same way.

\section{Moral dimension}

In terms of morality, participant 18 thought that survivors in the past perceived members of their group as people who wanted to exterminate them but now things have changed. "Currently, survivors perceive us as people with whom they are comfortable. This was not the case after the genocide. They perceived us like wild, guilty people who had no heart. I think the survivors saw non-victims as people who had nothing to give except kill. "However, there were two nonvictims who thought that survivors do not perceive all non-victims in the same way. "We believe that survivors perceive some members of our group as people who regret what they have done and others as people who can kill the survivors any time" (Int.17)

\section{Social dimension}

Concerning the social dimension, among the meta-stereotypes attributed to survivors by non-victims are those linked to the lack of 
confidence in the past. "Just after the period following the genocide, the survivors perceived us as people who should not be trusted. But it was understandable when we tried to consider what the survivors had just experienced or suffered "(Int.10). Two non-victims emphasized that they could not comment on how they think they are perceived by the survivors. "I cannot know how survivors perceive our group or what they think of us because I am not in their hearts. However, I can say that in our relations there is no problem, it is ordinary life. I think it is really difficult to pronounce myself on it "(Int 13). All of the metastereotypes of how non-victims think they are perceived by survivors generally relate to the period that directly followed the Tutsi genocide. These meta-stereotypes highlight the immorality of non-victims. In sociability, there is a single meta-stereotype showing that members of both groups felt that the members of their in-group were perceived by the members of the out-group as being cold. No meta-stereotypes of competence were mentioned by non-victims. We have just seen that, in the past, survivors perceived non-victims as immoral and cold, and that things have changed now. In turn, the non-victims thought that they were perceived by the survivors as cold and immoral and this had changed with time. In the next section, we will discuss the stereotypes attributed to the survivors.

\section{Stereotypes attributed to survivors by non-victims}

The results show that six out of 10 non-victims who attributed the stereotypes of coldness reported a certain evolution, a change as the years passed. They pointed out that at the time of interview things were going well. Among these six non-victims, only one spoke about the heterogeneity of the group of survivors, which plays a role in the attribution of stereotypes. Two non-victims among the six emphasized that they attributed certain stereotypes to survivors that are specific to the period of commemoration. Two non-victims only attributed stereotypes in relation to valued status and the moral dimension.

\section{Moral dimension}

Concerning the social dimension, participant 20, a non-victim, emphasized that the survivors were also perceived as threatening: "We perceived the survivors as people who could take revenge at any moment, but at present things have changed, we no longer fear. "However, non-victim participant 17 did not perceive all survivors in the same way: "There are survivors who have gone beyond what happened during the genocide and who do not think much about for whom life goes on. And others who are always resentful and always want to harm non-victims. "(int 20)

\section{Social dimension}

On the social level, survivors were perceived by six out of ten nonvictims as wounded and deeply sad during the post-genocide period. This sadness prevented them from approaching the non-victims, but now they had made great strides and the proof is that some were able to forgive the non-victims. Nevertheless, participant 17 did not perceive all survivors as vulnerable to the same degree: "There are survivors who have gone beyond what has happened, who are in good contact with the non-victims. And others who do not feel them and do not like the non-victims". To this, the same participant added that the period of commemoration is a period in which negative perceptions are exacerbated: “... during the period of commemoration, survivors remember what happened: their families members, the parents they have lost. (...) Non-victims perceive survivors as people to whom they can not speak during this period. "Commemoration is a sensitive period that turns survivors back into the past, revives, and accentuates and changes perceptions and relationships.

\section{Valorized status}

In terms of higher status, the stereotypes attributed to survivors show that they are perceived as having a valued status. "I can say that I perceive survivors as lucky people because they are positively perceived in society. The survivors can neither feel the shame of their group nor be accused of genocide "(Int. 18). The results show that the stereotypes that the non-victims attributed to survivors are related to the moral and social dimensions, and higher status. In the aftermath of the genocide, the non-victims perceived the survivors as cold but right now things are going well. In the past there was no contact between the non-victims and the survivors but there was progress and with increased contact came a diminishment of negative stereotypes. The period of commemoration is a period that emphasizes this distance, however, and during which survivors are perceived by the nonvictims as people who cannot approach the non-victims. Survivors have a valued status that allows them to escape guilt. ${ }^{48}$ Regarding the moral dimension, survivors pose a threat to non-victims. Survivors are perceived by most non-victims as cold and by some non-victims as immoral and holding a valued status. In the next section, we will discuss how survivors think they are perceived by the non-victim.

\section{The meta-stereotypes attributed by survivors to the non-victims}

Two survivors believed they are perceived by non-victims as immoral. In terms of sociability, nine out of ten survivors believed that non-victims perceived them as cold. Only one participant showed the difference between the meta-stereotypes that survivors attributed in the past and what they currently attribute to non-victims. The group's variability in meta-stereotyping was also mentioned by the same participant. In terms of valorized status, seven out of ten survivors believed that non-victims perceived them as people with valued status.

\section{Moral dimension}

Among the meta-stereotypes attributed to non-victims in morality are those related to the fact that survivors believe that they constitute a threat to non-victims. "In the head or the thoughts of a non-victim, as a survivor, I am someone who seeks to harm him and seeks revenge" (int 7).

\section{Social dimension}

In relation to the social dimension, all survivors except one thought that they were perceived by the non-victims as enemies, but that at the time of the investigation things had changed. "Before, the non-victims perceived us as enemies but at the moment, you find that there are certain non-victims who have a heart. They see us as people, with whom they can be happy. Others are always ashamed and perceive us as people whom they are afraid to approach "(Int 12). On the other hand, participant 5 thought that the non-victims perceived the survivors as their witnesses to the charge: "Personally, I can say that we live as enemies. Non-victims perceive us as people who have testify against them during Gacaca juridictions, and caused their incarceration. We testified to show what they did and they were punished according to the law"(int 5). Participant 5 tended to consider all non-victims as culpable and her remarks tell us that Gacaca jurisdictions have a role to play in intergroup perceptions and creating new stereotypes. 


\section{Valorized status}

The meta-stereotypes attributed to non-victims by survivors in terms of competence can be divided into three categories: metastereotypes that show the non-victims perceived the survivors as people who have been self reliant after the genocide; as people who can never be suspected of involvement in genocide, or as people who benefit from assistance provided after the genocide. As participant 6 points out, some survivors think that they are perceived by the nonvictims as people who have been self reliant: "Personally, non-victims perceive members of our group as people who have been self reliant from nowhere. Widows have been self reliant and move positively in life. The non-victims thought it was over for the survivors. The nonvictims could not imagine that the survivors could became self reliant as they are today ". Survivors believed that they were envied by the non-victims not only for their self reliance but also for the assistance they receive from the Fund to Assist Genocide Survivors. "We think there are some non-victims who perceive us positively and other non-victims who are jealous of us. They are not happy with the fact that survivors are helped by the Fund for Assistance to Genocide survivors. They perceive us as people who have advantages" (Int 16).

These benefits are not only material, but survivors think that they are perceived by non-victims as having psychological advantages: "I think that the non-victims perceive the members of our group as the people they envy. Because we were lucky to belong to a group that does not make us ashamed"(Int.2). According to participant 2, having the status of survivor permitted them to escape guilt and to access to a positive image. These meta-stereotypes attributed to the survivors confirmed the stereotypes that survivors attributed to nonvictims. Survivors were perceived by most non-victims as cold and, by only a few, as immoral and with a valorized status. Most survivors believe that non-victims perceive them as cold and with a valued status. In accordance with the needs-based reconciliation model these stereotypes and meta-stereotypes reflect the survivors' threat to restore this valued status and power. For non-victims, these stereotypes and meta-stereotypes highlight the moral image and the rejection of their group. However, for most participants, these stereotypes and metastereotypes concerned the past, and a few of them emphasized the group heterogeneity in stereotypes and meta-stereotype attribution.

\section{Discussion}

Our findings had shown that the threats to social identity whose suffer victims and members of perpetrators group after a conflict according to the needs based model ${ }^{11}$ have appeared in the content of the stereotypes and meta-stereotype attribution. These stereotypes and meta-stereotypes that survivors and non-victims attribute to each other are structured along three dimensions: moral, social and agency. The results of the interviews show that the stereotypes and meta-stereotypes related to having a valued status concerned only the survivors. No such attribution was made for non-victims. Survivors believed that they were perceived by non-victims as having valued status and benefits. The dimensions of sociability and morality appeared in the attributions of both groups. The two groups perceived themselves, and thought that the out-group perceived them, as cold and immoral We would like to emphasize that the immorality of survivors is about revenge and the fact that survivors posed a threat to non-victims. This immorality falls within the framework of status valued in the eyes of the survivors because it goes in the direction of restoring power. These results are consistent with the needs-based socio-emotional reconciliation model. The restoration of power is sought after by the victims who lost it during the conflict. ${ }^{11}$ The moral image and acceptance by the victim group are sought by the perpetrators who had tarnished their image by becoming negatively involved in the conflict.

Indeed, the results showed that the meta-stereotypes confirmed the stereotypes. The manner in which members of the surviving group perceived those of the non-victim group, and vice versa was the way the non-victim group thought they were perceived by the survivors, and vice versa. The stereotypes attributed to non-victims and the meta-stereotypes attributed to survivors by non-victims were cold and immoral. The stereotypes attributed to the survivors and the meta-stereotypes attributed to the non-victims by the non-victims concerned coldness and valued status. In general, these various attributions concerned the past, except the valued status. According to our participants, at the time of the survey things were beginning to change. These results highlight the time effect in improving intergroup relation. The findings from this study have demonstrated that the nonvictims and survivors perceived in 2011 that the relations between the Rwandan communities were warm but just after genocide cold they estimated that these relations were cold.

Moreover, for some participants, the negative stereotypes and meta-stereotypes attribution did not concern the whole group. The non homogenization of non-victim group is a phenomenon which should be fostered in the reconciliation process. Different studies have revealed that the distinction among the members of perpetrators, victims, bystanders, the passive and the moral exemplars constitutes the key in strengthening optimistic beliefs in reconciliation. ${ }^{49}$ Though that post-conflict situation has a reality which is different from periods of peace, we think that evolution over time and this group variability can play the role of compensating or attributing ambivalent stereotypes observed in cooperative or non-confrontational situations. ${ }^{6,25}$ However, we don't have sufficient data for testing this hypothesis. A study that will examine if in post conflict or genocide context, the evolution of attitudes over time and group variability play compensating roles in stereotypes should be conducted in the future.

Despite the time and group variability, the results of this study show that some programs or policies put in place by the Rwandan government in post-genocide management play an important role in the process of stereotypes and meta-stereotype attribution. These programs are the Gacaca jurisdictions, the Funds for Assistance to Genocide Survivors and the Commemoration. There are metastereotypes attributed by survivors to non-victims who are related to the Gacaca juridictions. Survivors believed that non-victims perceived them as people who have testified against them during Gacaca jurisdictions. In addition, the Genocide Survivors Assistance Funds contributed after the genocide to the reconstruction of the lives of survivors who have become autonomous and self reliants. They thought that they were perceived as people with benefits, who are supported by the government because they receive assistance. They perceived themselves as having a valued status that can be envied by the non-victims. Commemoration is a sensitive period during which the relations between non-victims and survivors change. Some participants mentioned that there are some stereotype attributions that appear only during the period of commemoration of genocide against Tutsi. 


\section{Conclusion}

Overall, the results underscore that Our findings had shown that the threats to social identity whose suffer victims and members of perpetrators group after a conflict according to the needs based model ${ }^{11}$ were reflected in the attribution of meta-stereotypes and stereotypes. Members of survivors groups were often stereotypically perceived at the time of the interview as having valorized status but were perceived as cold and immoral in the period following the genocide. In contrast, members of the non-victim groups with inferior status were perceived as cold and immoral in the period following the genocide. ${ }^{50}$ The evolution over time and resistance to group homogenization has been advanced as having an impact in the stereotype and meta-stereotype attribution and intergroup relations. Finally the present study also demonstrated that some programs or policies implemented by the Rwandan government in post-genocide management play an important role in the stereotypes and meta-stereotypes that survivors and nonvictims attribute to each other. Our findings suggested several future research directions. One future study could explore responses in more depth and examine also if the colonial stereotypes about the ethnic group are still persistent. Another study can examine if in post conflict or genocide context, the evolution over time and group variability play a compensating role in stereotype attribution.

\section{Limitation}

We recruited a convenience sample. Our simple was diverse in terms of age, gender norms and social identity. Unfortunately, selfselection bias regarding who is willing to talk a would change what people might report in an interview. Only those open to discussing these issues would have volunteered. Additionally, university educated may have different views than these with lower education and they represent a minority of the Rwandan people. Given that our analysis highlights the importance of the social context in peoples' stereotypes and meta-stereotypes attribution to their in-group and outgroup and the link between these attributions and threats related to social identity whose suffer victims and members of perpetrators after a conflict according to Needs Based Model, similar in-depth analyses of these processes with a larger sample which can consider intracategorical difference are needed. A sample from where the group membership can safely be inferred such us young and old people, old versus new refugees, survivors, prisoners, people who participated in Gacaca, people from urban area versus rural area etc.

\section{Acknowledgements}

None.

\section{Conflict of interest}

The author declares that there is no conflict of interest.

\section{References}

1. Shnabel N, Nadler A, Ullrich J, et al. Promoting reconciliation through the satisfaction of the emotional needs of victimized and perpetrating group members: The needs-based model of reconciliation. Pers Soc Psychol Bull. 2009;35(8):1021-1030.

2. Turner JC, Hogg MA, Oakes PJ, et al. Re-discovering the social group A self-categorization theory. British Journal of Social Psychology. 1987;26(4):195-217

3. Tajfel H, Turner JC. The social identity theory of intergroup behavior In: Worchel S, et al. editors. The psychology of intergroup relations. Chicago: Nelson-Hall; 1986. 7-24 p.
4. Leach CW, Ellemers N, Barreto M. Group virtuel: The importance of morality (vs competence ans sociability) in the positive evaluation of in-group. J Pers Soc Psychol. 2007;82:878-902.

5. Dubois NL, Beauvois JL. The social value of internal explanations and the norm of internality. Personality and Social Psychology. 2008;2(4):1737-1752.

6. Fiske ST, Cuddy AJC, Glick P, et al. A model of often mixed stereotype content: Competence and warmth respectively follow from perceived status and competition. Journal of Personnality and Social Psychology. 2002;82(6):878-902.

7. République Rwandaise, Présidence de la République. Recommandations de la conférence tenue à Kigali du 1er au 5 novembre1995 sur le thème: Génocide, impunité et responsabilité:Dialogue pour l'élaboration d'une réponse au niveau national et international. Kigali, Rwanda: La Présidence; $1995.48 \mathrm{p}$

8. Rouhanna NN. Identity and Power in the Reconciliation of national conflict. In AH Eagly, et al. editors. The social psychology of group identity and social conflict: Theory, application, and practice. Washington, DC: Psychological Association; 2004. 173-187 p.

9. Rouhana NN. Group identity and power asymmetry in reconciliation processes: the israeli-palestinian case. Journal of Peace Psychology. 2004;10(1):33-52.

10. Kelman HC. Reconciliation from a social psychological perspective. In Nadler A, et al. editors. The social psychology of intergroup reconciliation. UK: Oxford University Press; 2008.15-32 p.

11. Nadler A, Shnabel N. Instrumental and socioemotional paths to intergroup and reconciliation and the needs-based model of socioemotional reconciliation. In AE Nadler, et al. editors. The social psychology of ntergroup reconciliation. New York: Oxford University Press; 2008. $37-56 \mathrm{p}$.

12. Foster CA, Rusbult CE. Injustice and Power seeking. Personality and social Psychology Bulletin. 2010;25(7):834-849.

13. McCullough ME, Rachal KC, Sandage SJ, et al. Interpersonal forgiving in close relationships II: Theoretical elaboration and measurement. $J$ Pers Soc Psychol. 1998;75(6):1586-1603.

14. Zechmeister JS, Romero C. Victim and offender accounts of interpersonal conflict: Autobiographical narratives of forgiveness and unforgiveness. Journal of Personnality and Social psychology. 2002;82:675-686.

15. Nadler A. Post resolution processes: Instrumental and socio-emotional routes to reconciliation. In: Salomon G, et al. editors. Peace education: The concept, principles, and practices around the world. Mahwah, NJ: Lawrence Erlbaum; 2002. 31 p.

16. Baumeister RF, Stillwell A, Wotman SR. Victim and perpetrator accounts of interpersonal conflict: autobiographical narratives about anger. J Pers Soc Psychol. 1990;59(5):994-1005.

17. Tavuchis N. Mea culpa: A sociology of apology and reconciliation. Stanford, CA: Stanford University Press;1991. 196 p.

18. Baumeister RF, Stillwell AM, Heatherton TF. Guilt: an interpersonal approach. Psychol Bull. 1994;115(2):243-267.

19. Bandura A. Moral disengagement in the perpetration of inhumanities. Pers Soc Psychol Rev. 1999;3(3):193-209.

20. Schönbach P. Account episodes: The Management or escalation of conflict. New York: Cambridge University Press; 1990. 222 p.

21. Schönbach P. Account episodes: The management or escalation of conflict. New York: Cambridge University Press; 2010. 385 p.

22. Akhtar S. Forgiveness: Origins, dynamics, psychopathology, and technical relevance. Psychoanal Q. 2002;71(2):175-212. 
23. Minow M. Between vengence and forgiveness. Facing history after genocide and mass violence. Boston: Beacon Press; 1998. 211 p.

24. Shnabelet Nadler. The role of agency and morality in reconciliation processes: the perspective of the needs-based model. Association of psychological sciences. 2015;1-7.

25. Kervyn N, Yzerbyt V, Judd C. When compensation guides inferences: Indirect and implicit measures of the compensation effect. European Journal of Social Psychology. 2011;41(2):144-150.

26. Yzerbyt VY, Kervyn N, Judd CM. Compensation versus halo: The unique relations between the fundamental dimensions of social judgment. Pers Soc Psychol Bull. 2008;34(8):1110-1123.

27. Abele AE, Wojciszke B. The Big Two in social judgment and behavior [Editorial]. Social Psychology. 2013;44(2):61-62.

28. De Bruin ENM, Van Lange PAM. what people look for in others: influences of the perceiver and the perceived on information selection. Personality and Social Bulletin. 2000;26:206-219.

29. Van Lange PAM, Kuhlman DM. Social value orientations and impressions of partner's honesty and intelligence: A test of the might versus morality effect. Journal of Personality and Social Psychology. 1994;67(1):126-141.

30. Van Lange PAM, Liebrand WBG. The influence of other's morality and own social value orientation on cooperation in the Netherlands and the USA. International Journal of Psychology. 1991;26(4):429-449.

31. Skowronskiet, Carlston. When status differences are illegitimate, groups' needs diverge: Testing the needs-based model of reconciliation in contexts of status inequality. European Journal of Social Psychology.1987. 280 p.

32. Judd L Hawkins, Yzerbyt V, KashimaY. Fundamental dimensions of social judgment: understanding the relations between judgments of competence and warmth. J Pers Soc Psychol. 2005;89(6):899-913.

33. Phalet K, Poppe E. Competence and morality dimensions in national and ethnic stereotypes: A study in six eastern-European countries. European Journal of Social Psychology. 1997;27(6):703-723.

34. De Bruin ENM, Van Lange PAM. The double meaning of a single act: Influences of the perceiver and perceived on cooperative behavior. European Journal of Personality. 1999;13(3):165-182.

35. Abele AE, Wojciszke B. Agency and communion from the perspective of self versus others. J Pers Soc Psychol. 2007;93(5):751-763.

36. Cambon L, Djouari A, Beauvois JL. Social judgment norms and social utility: when it is more valuable to be useful than desirable. Swis Journal of Psychology. 2006;65(3):167-180.

37. Iyer A, Leach CW. Helping disadvantaged out groups challenge unjust inequality: The role of group based emotions. In: Stürmer S et al, editors. New directions in the psychology of helping: Group-level perspectives on motivations, consequences, and interventions. Oxford: Blackwell; 2010. 337-353 p.
38. Crocker J, Blaine B, Luhtanen R. Prejudice, intergroup behaviour and self-esteem: Enhancement and protection motives. In MA. Hogg, et al editors. Group motivation: Social psychological perspectives. England: Harvester Wheatsheaf; 1993. 52-67 p.

39. Luhtanen R, Crocker J. A collective self-esteem scale: Self-evaluation of one's social identity. Personality and social psychology Bulletin 1992;18(3):302-317.

40. Tafarodi RW, Swann WB. Self-linking and self-competence as dimensions of global self-esteem: initial validation of a measure. Journal of Personality Assessment. 1995;65(2):322-342.

41. Blanz M, Mummendey A, et Otten S. Positive-negative asymmetry in social discrimination: The impact of stimulus valence and size and status differentials on intergroup evaluations. British Journal of Social. 1995;34(4):409-419.

42. Ellemers N, Van Rijswijk W. Identity needs versus social opportunities: The use of group-level and individual-level identity management strategies. Social Psychology Quarterly. 1997;60:52-65.

43. Bettencourt B, Charlton K, Dorr N, et al. Status differences and in-group bias: a meta-analytic examination of the effects of status stability, status legitimacy, and group permeability. Psychol Bull. 2001;127(4):520-542.

44. Pagliaro S, Ellemers N, Baretto M. Sharing moral values: Anticipated ingroup respect as a determinant of adherence to morality-based (but not competence-based) group norms. Personality and social psychology Bulletin. 2011;37(8):1117-1129.

45. Galtung J. Violence, peace and peace research. Journal of Peace Research. 1969;6(3):167-191.

46. Fiske, Cuddy, Glick. Universal dimensions of social cognition: warmth and competence. Trends cogn Sci. 2007;11(2):77-83.

47. Siem B, von Oettingen M, Mummendey A, et al. When status differences are illegitimate, groups' needs diverge: Testing the needs-based model of reconciliation in contexts of status inequality. European Journal of Social Psychology. 2013;43(2):137-148.

48. Todorov T. Les abus de la mémoire. Paris: Arléa; 1998.

49. Cehajic-Clancy S, Bilewicz M. Fostering reconciliation through historical moral exemplars in a post-conflict society. Journal of Peace Psychology. 2016;23(3):288-296.

50. Kanazayire C, Licata L, Melotte P, et al. Does identification with Rwanda incease reconciliation sentiment between genocide survivors and nonvictims? The mediating role of perceived intergroup similarity and self-esteem during commemorations. Journal of Social and Political Psychology. 2014;2(1):489-504. 